\title{
ANÁLISE DA DISTRIBUIÇÃO TÉRMICA DA CIDADE DE CAMPO GRANDE, MATO GROSSO DO SUL, NO ANO DE 2015
}

\author{
SOUZA, Camila Amaro de - arq.camila.amaro@gmail.com \\ Universidade Anhanguera/UNIDERP \\ SILVA, Mauro Henrique Soares da - mauro.soares@ufms.br \\ Universidade Anhanguera/UNIDERP
}

\begin{abstract}
RESUMO: O ambiente urbano passa por constantes modificações no microclima de acordo com a interação entre os elementos climáticos e o relevo modificado pela ação humana, sendo este, o habitat para a maioria da população mundial. Dentro deste contexto, o conforto térmico vem elucidar a importância de manter correspondência entre o meio habitado e o clima local, objetivando qualidade de vida, principalmente, nos aspectos relacionados à sociedade, ambiente e desenvolvimento regional sustentável. Assim, o objetivo geral desta pesquisa foi analisar a distribuição espacial da temperatura e avaliar a influência de áreas verdes no conforto térmico na cidade de Campo Grande, no Estado de Mato Grosso do Sul. A metodologia consistiu em: revisão bibliográfica multidisciplinar, identificação da distribuição espacial de temperatura de superfície na área urbana por meio do uso de geoprocessamento confrontando tais dados com as temperaturas do ar adquiridas por meio da aplicação de transectos móveis no verão e no inverno de 2015 em vias principais da cidade, seguido da interpolação desses dados. Esta pesquisa buscou auxiliar na obtenção de informações mais precisas sobre a influência dos elementos climatológicos para o contexto urbano, podendo auxiliar o planejador urbano quanto à possibilidade de trabalhar alternativas de organização dos espaços com ênfase em critérios ambientais, entre os quais, o de conforto térmico dos ambientes urbanos.
\end{abstract}

Palavras- chaves: Urbanização, qualidade de vida, análises climáticas, áreas verdes.

ANALYSIS OF THE THERMAL DISTRIBUTION OF THE CITY OF CAMPO GRANDE, MATO GROSSO DO SUL, IN THE YEAR 2015

\begin{abstract}
The urban environment goes through constant changes in the microclimate according to the interaction between environmental influences and relief modified by human action, which is the habitat for most of the world's population. Within this context, the thermal comfort is to elucidate the importance of maintaining correspondence between the inhabited environment and the local climate, aiming at quality of life, especially in aspects related to society, environment and sustainable regional development. . Thus, the general objective of this research was to analyze the spatial distribution patterns of climatic variables and evaluate the influence of green areas in the thermal comfort in the city of Campo Grande, in Mato Grosso do Sul The methodology consists of: multidisciplinary literature review, identification of the spatial distribution of thermal surface patterns in urban areas and urban heat island and freshness through geoprocessing use comparing such data to the ambient temperatures also acquired through the application of mobile transects in the summer and winter of 2015 main roads of the city. This research aimed to assist in obtaining more accurate information on the influence of climatic elements to the urban context, therefore helping urban planner about the possibility of working alternatives for the organization of spaces with an emphasis on environmental criteria, including the thermal comfort urban environments
\end{abstract}

Keywords: urbanization, quality of life, climatic analysis, green areas.

ANÁLISIS DE LA DISTRIBUCIÓN TÉRMICA DE LA CIUDAD DE CAMPO GRANDE, MATO GROSSO DEL SUR, AÑNO DE 2015

RESUMEN: El entorno urbano pasa por constantes cambios en el microclima de acuerdo a la interacción entre los elementos climáticos y el alivio modificados por la acción humana, que es el hábitat de la mayor parte de la población mundial. Dentro de este 
contexto, el confort térmico es dilucidar la importancia de mantener la correspondencia entre el entorno habitado y el clima local, con el objetivo de calidad de vida, especialmente en los aspectos relacionados con la sociedad, el medio ambiente y el desarrollo sostenible de la región. . Por lo tanto, el objetivo de esta investigación fue analizar la distribución espacial de las variables climatológicas y evaluar la influencia de zonas verdes en el confort térmico en la ciudad de Campo Grande, en Mato Grosso do Sul La metodología consistió en: revisión de la literatura multidisciplinar, la identificación distribución espacial de la temperatura superficial de las zonas urbanas y de isla de calor urbano y frescura a través del uso de geoprocesamiento la comparación de estos datos con la temperatura del aire adquirida por la aplicación de transectos móviles en verano y en invierno de 2015, de las calles principales de la ciudad seguido por interpolación de estos datos. Esta investigación tuvo como objetivo ayudar en la obtención de una información más precisa sobre la influencia de los elementos climatológicos para el contexto urbano y puede ayudar al planificador urbano en cuanto a la posibilidad de trabajar organización alternativa de los espacios con un énfasis en criterios ambientales, incluyendo la comodidad térmica entornos urbanos.

Palabras Clave: urbanización, calidad de vida, análisis del clima, zonas verdes

\section{ANÁLISIS DE LA DISTRIBUCIÓN TÉRMICA DE LA CIUDAD DE CAMPO GRANDE, MATO GROSSO DEL SUR, AÑO DE 2015}

RÈSUMÉ: L'environnement urbain passe par des changements constants dans le microclimat selon l'interaction entre les éléments climatiques et de secours modifiés par l'action humaine, qui est l'habitat pour la plupart de la population mondiale. Dans ce contexte, le confort thermique est d'élucider l'importance de maintenir la correspondance entre l'environnement habité et le climat local, en vue de la qualité de vie, en particulier dans les aspects liés à la société, l'environnement et le développement régional durable. . Ainsi, l'objectif de cette recherche était d'analyser la distribution spatiale des variables climatologiques et d'évaluer l'influence des espaces verts dans le confort thermique dans la ville de Campo Grande, dans le Mato Grosso do Sul La méthodologie a consisté en: revue de la littérature multidisciplinaire, identification distribution spatiale de la température de surface des zones urbaines et îlot de chaleur urbain et fraîcheur grâce à l'utilisation géotraitement comparant ces données avec la température de l'air acquise par l'application de transects mobiles en été et en hiver 2015 dans les principales artères de la ville suivie par une interpolation de ces données. Cette recherche visait à aider à obtenir des informations plus précises sur l'influence des éléments climatologiques pour le contexte urbain et peut aider l'urbaniste à la possibilité de travailler organisation alternative des espaces en mettant l'accent sur des critères environnementaux, y compris le confort thermique environnements urbains.

Mots-Clés: urbanisation, qualité de vie, analyse du climat, espaces verts.

\section{INTRODUÇÃO}

O crescimento urbano nos últimos anos trouxe consequências para o meio ambiente que podem ser observadas devido à degradação da vegetação densa e o aumento da quantidade de prédios e pavimentação asfáltica. Propiciando o desconforto térmico que pode ser observado pela alteração do clima devido a ação antrópica na superfície.

As ilhas de calor são exemplos destas ações, formadas em áreas urbanas e suburbanas a partir de seus déficits de vegetação e uso de materiais de construção que retém mais calor do sol do que materiais naturais em áreas rurais menos urbanizadas (Gartland, 2010). Como a questão das ilhas de calor acompanha o crescimento urbano, têm surgido muitas propostas metodológicas de estudo através das geotecnologias, no qual vem se destacando o uso do sensoriamento remoto para auxiliar a atingir resultados que, acompanhados de chave de interpretação em campo, demonstram as características de forma 
urbana, como cobertura das superfícies, e variáveis ambientais como a temperatura do ar, temperatura de superfície e dados de radiação incidente.

Nessa perspectiva o objetivo deste trabalho consistiu em uma análise de dados de temperatura da cidade de Campo Grande, capital de Mato Grosso do Sul. Como objetivos específicos: identificar a distribuição espacial dos dados de temperatura de superfície bem como da temperatura do ar na área urbana de Campo Grande, além de identificar e mapear as regiões mais quentes e mais frescas da cidade e de seu entorno próximo.

O trabalho se justifica por ser um exemplo de como as características climáticas influenciam no bem estar da população e contribuem para que diretrizes de conforto térmico ambiental sejam acrescentadas ao planejamento urbano de municípios.

\section{ÁREAS DE ESTUDO E SUAS CARACTERÍSTICAS}

O Município de Campo Grande, com $8.096 \mathrm{~km}^{2}$, está localizado geograficamente na porção central de Mato Grosso do Sul, ocupando 2,26\% da área total do Estado. A sede do município localiza-se nas imediações do divisor de águas das Bacias do Paraná e Paraguai, estando definida pelas coordenadas

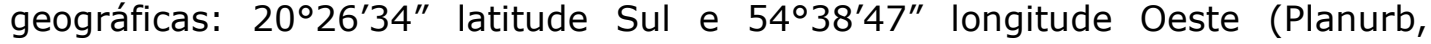
2007).

Tem como municípios limítrofes: Jaraguari, Rochedo, Nova Alvorada do Sul, Ribas do Rio Pardo, Sidrolândia e Terenos, e possui dois distritos: Anhanduí e Rochedinho, que passaram a ser considerados Regiões Urbanas para fins de planejamento, através da Lei Complementar $n^{\circ} 5$, de 22 de novembro de 1995, que institui o Plano Diretor de Campo Grande. O perímetro delimitado para área de estudo está de acordo com o zoneamento utilizado pela prefeitura municipal e está dividido em sete (7) Regiões Urbanas: Centro (13 bairros), Prosa (10 bairros), Bandeira (10 bairros), Anhanduizinho (12 bairros), Lagoa (10 bairros), Imbirrussu ( 7 bairros) e Segredo ( 7 bairros) (Planurb, 2010).

O clima, segundo a classificação de Köppen para a cidade de Campo Grande, situa-se na faixa de transição entre o subtipo Cfa-mesotérmico úmido sem estiagem - em que a temperatura do mês mais quente é superior a $25^{\circ} \mathrm{C}$, tendo o mês mais seco mais de $30 \mathrm{~mm}$ de precipitação e o subtipo Aw - tropical úmido com estação chuvosa no verão e seca no inverno. Cerca de $80 \%$ das chuvas ocorrem entre os meses de outubro até abril, quando a temperatura média oscila em torno de $24^{\circ} \mathrm{C}$. Os meses de menor precipitação são: junho, julho e agosto e a temperatura média é de $20^{\circ} \mathrm{C}$. Os déficits hídricos ocorrem com maior intensidade nesses meses, onde a média das temperaturas mínimas é abaixo de $15^{\circ} \mathrm{C}$. O mês mais seco é o mês de agosto (Planurb, 2010). 


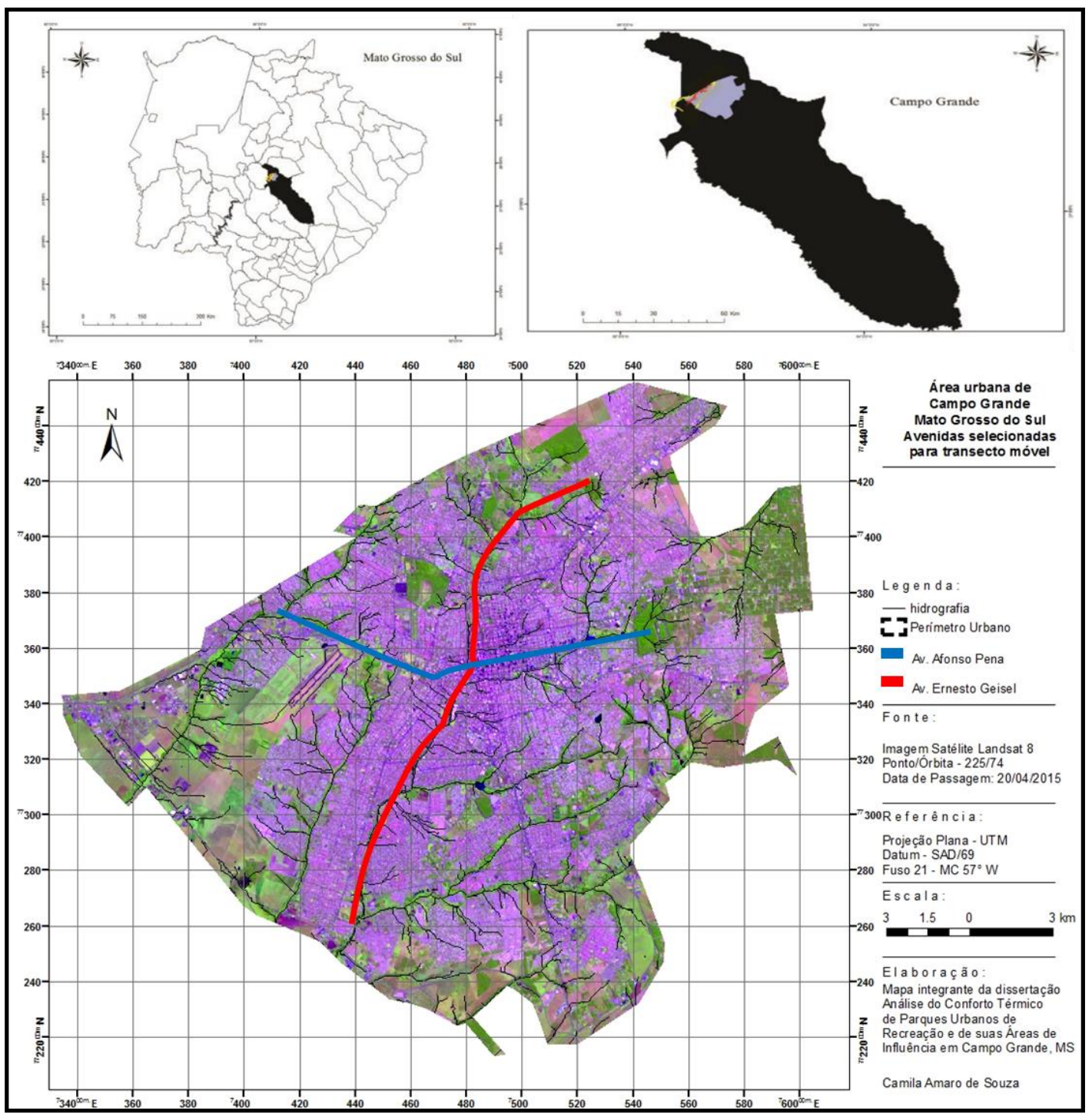

Figura 1 - Mapa de localização da área de estudo. Fonte: adaptado de Yamaciro (2007).

O crescimento dos loteamentos em Campo Grande esteve ligado à implantação da linha férrea que cortava a cidade, a área de maior densidade de ocupação é na região urbana Centro e no seu entorno imediato; seguido pelas vias de acesso (Corredores) que se difundem no sentido da periferia da cidade. A porção nordeste, sudeste, sudoeste e noroeste são as regiões onde os loteamentos têm a menor ocupação, por serem áreas destinadas à ocupação industrial (Planurb, 2010).

O fluxo de maior intensidade entre as periferias e o centro da cidade se faz comumente por duas principais vias de acesso: a Avenida Afonso Pena e a Avenida Ernesto Geisel (figura 1). Ressalta aqui que a análise dessas duas principais avenidas foi essencial para a realização da etapa de coleta de dados de campo desta pesquisa e para o processamento dos dados obtidos. 
A Avenida Afonso Pena inicia seu trajeto na Região Urbana do Centro, região altamente adensada e impermeabilizada, próxima à Avenida Duque de Caxias e se finda no bairro Chácara Cachoeira, região conhecida como Altos da Avenida Afonso Pena, próximo ao Parque das Nações Indígenas e Parque dos Poderes, à leste da cidade, setor residencial e com a presença de maior quantidade de áreas verdes do perímetro urbano. Na avenida estão localizados alguns dos principais pontos históricos e comerciais. É uma via arterial e de principal fluxo no sentido leste - oeste do perímetro urbano.

A Avenida Ernesto Geisel tem início no rodoanel, a sul do perímetro urbano, em bairro residencial de baixo adensamento e zona industrial da cidade, região altamente impermeabilizada e representa o setor com menores índices de vegetação (Souza, 2016). Cruza toda a cidade no sentido sul - norte, passando pela área central na altura da Avenida Afonso Pena e estendendo-se até a porção noroeste da cidade com a presença de vegetação densa e vazios urbanos neste ponto, bem como áreas de ocupação residencial. É uma via arterial de fluxo intenso, e ao longo de seu eixo encontra-se o córrego Anhanduí praticamente todo canalizado, mas ainda com alguma representatividade no que diz respeito à vegetação, possuído ao longo de todo seu percurso a presença de árvores ou vegetação de pequeno porte.

\section{MATERIAL E MÉTODOS}

Para o alcance dos objetivos específicos desta pesquisa foram realizadas as etapas de coleta de dados de campo por meio dos transectos móveis e chave de interpretação, e posterior processamento digital de imagem orbital. A utilização destas metodologias de compreensão do campo térmico no espaço urbano e rural tem obtido êxito e favorecem as correlações entre temperatura de superfície e do ar (Oke, 2003).

Para todos os processamentos digitais foi utilizado o software IDRISI Selva como base principal. Para a compreensão da temperatura de superfície foram utilizados dados de imagem de satélite Landsat-8, órbita e ponto (225/74), data de passagem 26/04/2015, as imagens disponíveis com datas anteriores, representativas de verão, estavam encobertas ou parcialmente encobertas por nuvens, impedindo a sua utilização para processamento de dados.

\section{AQUISIÇÃO DE DADOS DE TEMPERATURA DO AR}

De acordo com Geiger (1990), a altura adequada para a coleta de temperaturas do ar oscila entre 1,25 e 2,00 metros, onde existe menor interferência de obstáculos próximos ao solo. Mesmo em distâncias pequenas, os valores de temperatura podem sofrer grandes variações que estão relacionadas às condições de entorno próximas aos locais de monitoramento, sejam elas: relevo, teor de vapor d'agua ou ocupação do solo (concentração de edificações, tipos de vegetação, tipos de pavimentação).

Os transectos móveis têm sido amplamente divulgados na literatura para o diagnóstico das ilhas de calor urbanas, a exemplo dos trabalhos realizados por Mendonça (1994), Yamashita et al. (1996); Monteiro (1997); Pitton (1997); Stewart (2000), Amorim (2005), Ugeda Júnior (2011). Um transecto móvel 
implica percorrer um trajeto com auxilio de um veículo e registrar as temperaturas em lugares representativos por meio de sensor instalado na parte externa do automóvel. Uma haste faz com que o equipamento fique entre 1,5 e 2,0 metros acima do nível do solo.

Para a verificação das temperaturas do ar intraurbana, no período noturno em Campo Grande às 20h, realizaram-se medidas em transectos móveis simultâneos nos percursos com sentidos sul-norte e leste-oeste, com aproximadamente $20 \mathrm{~km}$ cada, saindo da periferia, passando pelo centro, chegando ao extremo oposto da cidade. A coleta de dados com veículos requereu que o tempo gasto entre a medida do ponto inicial e no ponto final do itinerário não ultrapassasse uma hora, com velocidade em torno de $30 \mathrm{Km} / \mathrm{h}$, sem interrupções.

Estes registros foram realizados no verão (10 de fevereiro de 2015) e no inverno (14 de julho de 2015), para mostrar a distribuição espacial das temperaturas urbanas nas diferentes estações do ano.

Ressalta-se ainda que informações oficiais da Estação Meteorológica INMET A702 foram utilizadas neste trabalho para validar os dados coletados. Tal procedimento metodológico é importante, pois auxilia na detecção de informações referentes aos diversos aspectos térmicos de Campo Grande - MS. A Estação Meteorológica INMET A702 fica instalada na sede da Embrapa Gado de Corte, em área afastada à região central da cidade, próxima ao aeroporto Internacional de Campo Grande.

Nos dias anteriores aos da realização do transecto móvel de verão ocorreu precipitação, mas no dia 10/02/2015 não houve registro de precipitação em Campo Grande - MS. A temperatura média mínima do mês de fevereiro foi $20{ }^{\circ} \mathrm{C}$ e a média máxima $32{ }^{\circ} \mathrm{C}$. A temperatura média no mês de fevereiro de 2015 esteve entre 24 e $26^{\circ} \mathrm{C}$.

Nos dias anteriores ao transecto móvel de inverno não ocorreu precipitação, e no dia 14/07/2015 também não houve registro de chuvas. A temperatura média mínima do mês de julho foi $20^{\circ} \mathrm{C}$ e a média máxima $28^{\circ} \mathrm{C}$. A temperatura média de julho de 2015 esteve entre 17 e $21^{\circ} \mathrm{C}$.

Foram utilizados dois sensores digitais datalogger HOBOware modelo U10-003 e números de série 10123700 e 10114346 , acoplados a uma haste metálica com $1,5 \mathrm{~m}$ de comprimento na lateral direita de dois veículos. 0 horário de realização dos transectos é adequado para este tipo de registro, uma vez que as temperaturas não experimentam mudanças rápidas.

Os percursos tiveram início, na Avenida Afonso Pena, dentro do Parque dos Poderes, até o final da Avenida Duque de Caxias, constituindo o sentido leste - oeste da cidade. E no anel viário da Av. Gunter Hans seguindo pela Av. Ernesto Geisel até chegar ao seu prolongamento denominado Av. Presidente Heráclito, constituindo o sentido sul - norte da cidade.

Tal metodologia teve o acompanhamento da agência de trânsito responsável (AGETRAN) e da Guarda Municipal de Campo Grande - MS, auxiliando na continuidade de dados sem interrupções em semáforos, cruzamentos ou devido a intervenções de outros veículos.

Deste modo, esse procedimento forneceu dados de temperatura do ar de uma área suficientemente distinta, no que se refere às características e 
estrutura urbana, e possibilitou a inter-relação e interpolação dos dados de temperatura do ar para toda a malha urbana de Campo Grande.

\section{INTERPOLAÇÃO DOS DADOS DE TEMPERATURA DO AR}

Posteriormente realizou-se a interpolação dos dados de temperatura coletados e suas respectivas coordenadas geográficas por meio do comando Interpol (inverso do quadrado da distância), seguido de Interpolation, do software IDRISI Selva, pelo método do inverso da distância pesada, para se obter o padrão de variabilidade espacial, fornecendo duas imagens. Uma com os valores estimados da variável regionalizada e outra com os erros da estimação (resíduos), sendo esta útil para avaliar a qualidade dos valores estimados e inferir as áreas onde a estimação não foi satisfatória.

Este método possui como base a relação entre os valores e a distância, pontos próximos no espaço de análise tendem a ter valores mais parecidos do que pontos mais afastados.

Utiliza-se o comando INTERPOL, Gis Analysis - surface Analysis interpolation. Na janela INTERPOL, em distance weightexpoent estabelece-se o peso que a variável terá, ou seja, o expoente da distância.

\section{AQUISIÇÃO DE DADOS DE TEMPERATURAS RADIANTES DE SUPERFÍCIE}

A transformação dos valores da imagem de satélite Landsat-8, ponto e órbita (225/74), data de passagem 26/04/2015, da radiância faz com que seja possível identificar a distribuição espacial dos dados de temperatura de superfície na área urbana de Campo Grande e no seu entorno, o que possibilitou uma correlação com os dados de interpolação das temperaturas aferidas por meio dos transectos móveis de verão, e permitiu a identificação de altas e baixas temperaturas ao longo do perímetro urbano.

Para a geração da temperatura de superfície, foram utilizados os métodos de Coelho et al. (2013); Coelho e Correa (2013) na banda do infravermelho termal (banda 10) do satélite Landsat-8, que são fundamentados respectivamente na Equação (1) e na Equação (2) disponibilizadas pelo USGS (Serviço Geológico Americano) onde são utilizados os parâmetros fixos de conversão de níveis de cinza das imagens para a radiância.

$$
\mathbf{L A}=\mathbf{M L} * \mathbf{Q c a l}+\mathbf{A L}
$$

Quadro 1 - Elementos da fórmula por conversão para Radiância.

SiglaExplicação

Lᄉ Radiância espectral do sensor de abertura em Watts/ ( $\left.\mathrm{m}^{2} \mathrm{sr} \mu \mathrm{m}\right)$

ML Fator multiplicativo de redimensionamento da banda $10=3,3420 \mathrm{E}-04$

$\mathrm{AL}$ Fator de redimensionamento aditivo específico da banda $10=0.10000$

Qcal Valor quantizado calibrado pelo pixel em DN = Imagem banda 10 
$\operatorname{In}(K 1 / L \Lambda+1)$

Onde:

$\mathrm{T}=$ Temperatura efetiva do satélite em Kelvin (K)

K2 = Constante de calibração $2=1.321 .08(\mathrm{~K})$

$\mathrm{K} 1$ = Constante de calibração $1=774.89(\mathrm{~K})$

$\mathrm{L} \Lambda=$ Radiância espectral em Watts/ ( $\left.\mathrm{m}^{2} \mathrm{sr} \mu \mathrm{m}\right)$

Após esses procedimentos realizados na banda 10 do Landsat - 8, os valores de temperatura Kelvin foram subtraídos pelo seu valor absoluto, gerando um mapa de temperatura (imagem raster de temperatura) em graus Celsius $\left({ }^{\circ} \mathrm{C}\right)$ para a validação dos dados.

\section{RESULTADOS E DISCUSSÃO}

A figura 2 e a figura 3 mostram a distribuição térmica da Av. Afonso Pena e Av. Ernesto Geisel, respectivamente, a partir dos pontos coletados nos transectos móveis de verão. As temperaturas encontraram-se acima de $28{ }^{\circ} \mathrm{C}$, nas áreas de urbanização densa do centro, bem como na área industrial da cidade a sudoeste.

No início do transecto da Av. Afonso Pena (Figura 2), na porção leste da cidade, as temperaturas aferidas foram as mais baixas do percurso, em torno de $25{ }^{\circ} \mathrm{C}$, provavelmente devido à proximidade com áreas de vegetação densa como o Parque Estadual do Prosa, Parque dos Poderes e Parque das Nações Indígenas, salientando que a presença de vegetação propicia duas estratégias naturais de controle térmicos relevantes: sombreamento e evapotranspiração. Outro fator a ser considerado é a altitude da região, variando entre 700 e 750 $\mathrm{m}$, e o relevo é mais movimentado, sendo considerado ondulado, principalmente devido às drenagens que cortam a área, evidenciando a confluência dos córregos Prosa e Segredo nesta parte da região urbana.

A temperatura se eleva gradativamente com a proximidade à área central da cidade, altamente impermeabilizada e altamente adensada, atingindo temperaturas superiores a $28{ }^{\circ} \mathrm{C}$, e ao se afastar da zona de vegetação densa, comprovando que o tipo de uso e ocupação do solo provoca modificações na temperatura. Outro fator importante, em relação à hipsometria, é que a altitude na região urbana centro se encontra entre 450 e $600 \mathrm{~m}$, e o relevo é considerado plano.

Após passar pela área central, na qual predomina alto adensamento, as temperaturas voltam a decrescer à medida que se aproximam de outra área verde da cidade inserida no entorno do Comando Militar Oeste e proximidades do Aeroporto Internacional de Campo Grande, atingindo $27{ }^{\circ} \mathrm{C}$ e não ocorrem grandes oscilações até o final do trajeto, porção oeste, em área de grandes vazios urbanos e vegetação entremeados à alto adensamento e pavimentação asfáltica. Ainda na porção oeste da cidade, final do transecto móvel, a altitude 
varia entre 400 e $600 \mathrm{~m}$, e o relevo mostra-se menos movimentado que na porção leste, sendo considerado plano.

Cabe destacar que, de acordo com dados das estações automáticas INMET, nesse dia havia um vento muito fraco de sudeste que, associado às características de fundo de vale e grandes áreas verdes concentradas, foram responsáveis pela diminuição da temperatura, por volta de $3^{\circ} \mathrm{C}$, na zona leste da cidade e parte da zona norte, podendo-se afirmar, portanto, interferência das zonas rurais, nesses bairros, mesmo sendo densamente construídos.

Observou-se também a correlação inversa entre temperatura e umidade, ou seja, nas áreas onde as temperaturas detectadas foram mais elevadas, a umidade obteve seu menor valor, $73 \%$ de umidade relativa do ar, e nas áreas com registro de temperaturas mais amenas, os valores de umidade relativa do ar registrados estavam em torno de $90 \%$.

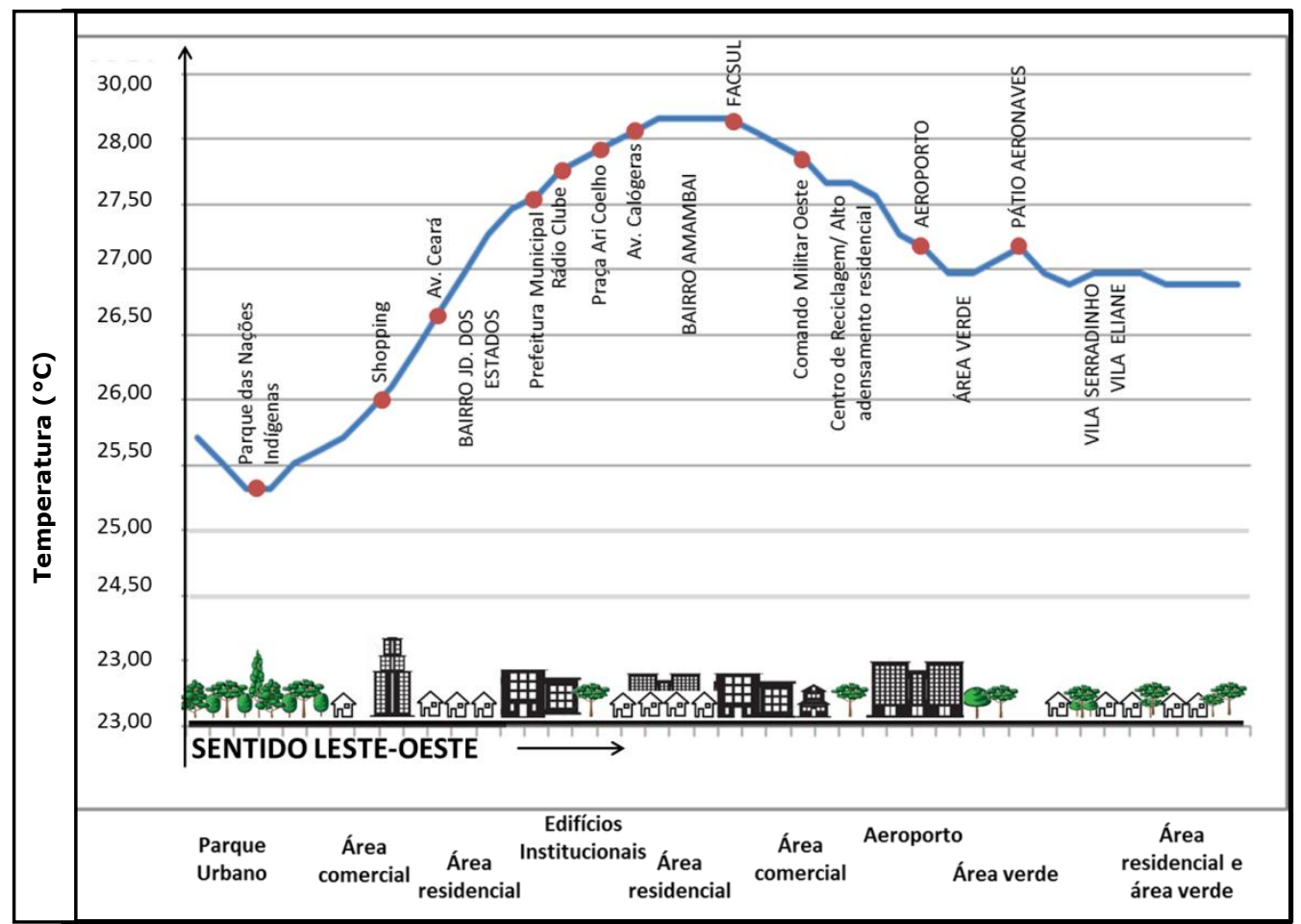

Figura 2 - Distribuição da temperatura ambiente na Av. Afonso Pena e Uso e ocupação do solo através do transecto móvel realizado no verão, 10 de fevereiro de 2015 , às $20 \mathrm{~h}$.

Cabe ainda salientar como referência a pesquisa de Mendonça (1994), em Londrina, no Estado do Paraná, que cita a mesma relação inversa entre temperatura e umidade na detecção de ilhas de calor urbanas e também utilizou metodologia semelhante de coleta de dados de temperatura do ar.

Outra consideração que pode ser realizada em relação a esta diferença na distribuição de temperaturas ao longo da Av. Afonso Pena, no verão de 2015, é a orientação das vertentes que na porção leste da cidade está voltada para sul e na porção final do trajeto, onde há o predomínio de áreas planas, se revelam com orientação oeste (Lima, 2011). Mostrando a diferença de radiação recebida, 
pois vertentes orientadas para sul recebem menor carga térmica que as orientadas para oeste.

A Figura 3 mostra a distribuição térmica na Av. Ernesto Geisel, apresentando temperaturas muito elevadas no início do transecto móvel, na região mais ao sudoeste da cidade, atingindo valores superiores a $28,6{ }^{\circ} \mathrm{C}$. Tal região compreende uma área industrial com rodoanel $\mathrm{e}$ alto índice de pavimentação asfáltica, e muitos galpões com coberturas metálicas, seguido de um hospital de grande porte.

Outros fatores importantes para o entendimento de altas temperaturas nesta região é o relevo plano, altitude entre 400 e 600 m, e orientação das vertentes estarem voltadas para oeste.

Dando continuidade ao percurso, próximo ao Parque Ayrton Senna a temperatura aferida foi de $28,5^{\circ} \mathrm{C}$. Provavelmente a temperatura elevada ocorre devido ao alto índice de impermeabilização no entorno do parque e alto índice de adensamento. Neste contexto, o aumento de temperatura de uma massa de ar pelo solo, em função da radiação solar absorvida, decorre principalmente do seu aquecimento por convecção (Lamberts et al., 2003).

Já de acordo com Romero (2000, p.37):

\begin{abstract}
"o ar em contato com a superfície que obteve ganhos de calor é, por sua vez, aquecido por condução; devido a este fenômeno, o calor adquirido é transferido às camadas superiores principalmente por convecção; assim as camadas inferiores ficam instáveis misturando-se constantemente com as camadas altas".
\end{abstract}

É correto afirmar também, de acordo com Romero (2000, p.25) que a presença de corpos d'água pode amenizar as "temperaturas extremas diurnas e estacionais" devido ao alto calor específico da água, constatando um acúmulo muito menor de temperatura nela do que no solo.

Em áreas de cobertura vegetal densa a amenização térmica é maior, pois grande parte da radiação solar absorvida é utilizada no processo metabólico das plantas, "irradiando uma quantidade menor de calor para o ambiente". Ao contrário, áreas com ausência de cobertura vegetal, como é o caso de pavimentação asfáltica e concreto, tendem a ter maiores variações térmicas, pois a energia solar absorvida é transformada em calor (Romero, 2000, p. 32).

O calor latente é a forma mais eficaz de resfriamento da superfície, pois ao transformar água líquida em gasosa, provoca a perda de energia através da transformação do calor sensível em calor latente, acarretando na queda de temperatura. O processo de urbanização diminui a evaporação e evapotranspiração, reduzindo assim, a perda de energia através da transformação do calor sensível em calor latente.

Isso ocorre, de acordo com Ugeda Júnior (2011), devido a um conjunto de fatores: às altas taxas de impermeabilização do solo, à retirada de vegetação e à canalização de córregos. Todos estes fatores potencializam o aquecimento das superfícies da área urbana, principalmente em função da diminuição de umidade nos espaços urbanos. 


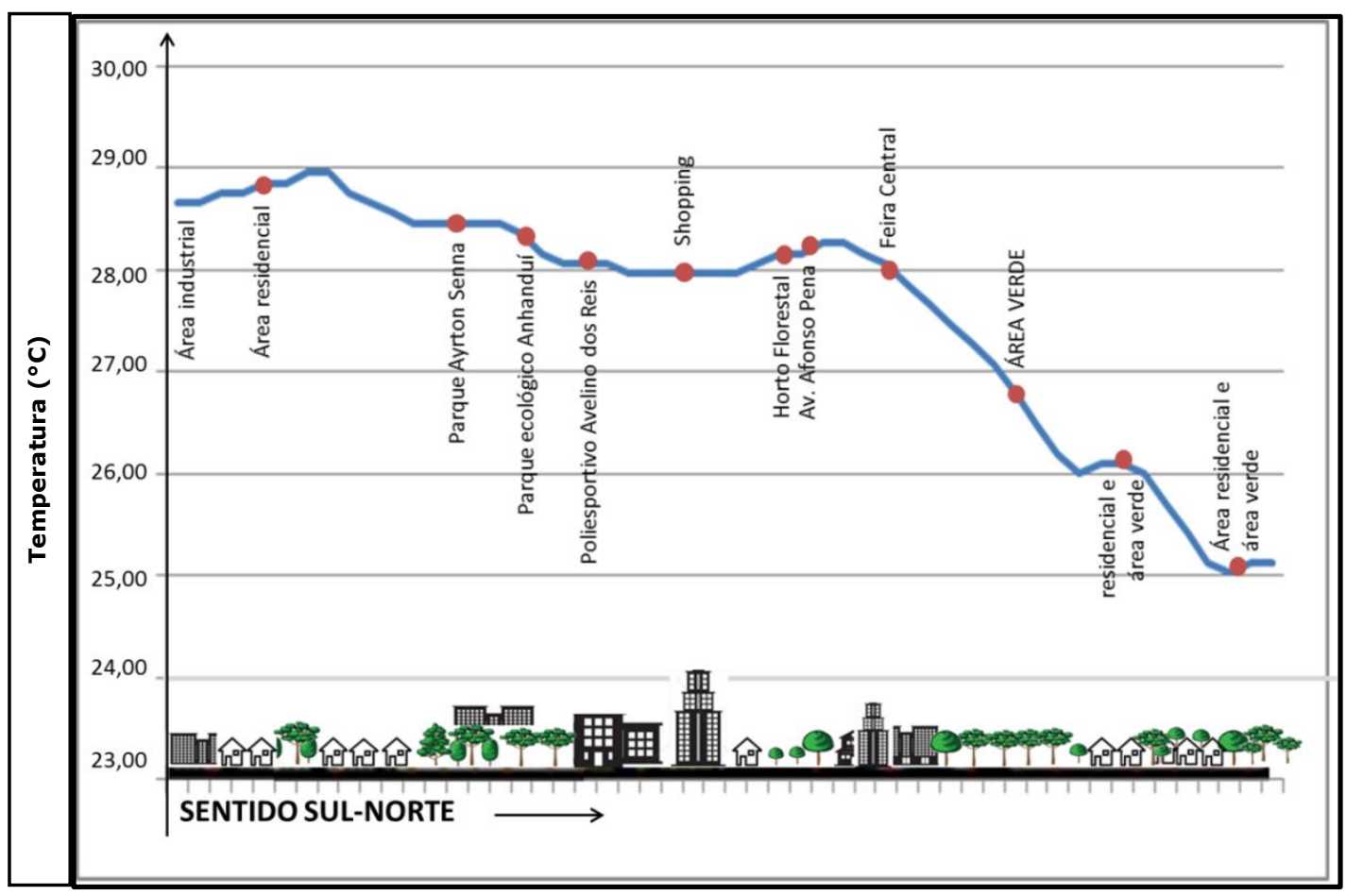

Figura 3 - Distribuição da temperatura ambiente na Av. Ernesto Geisel e Uso e ocupação do solo através do transecto móvel realizado no verão, 10 de fevereiro de 2015 , às $20 \mathrm{~h}$.

Continuando o trajeto, foram aferidas temperaturas elevadas na Região Urbana do Centro, denominada para esta pesquisa como urbanização densa, entre 28 e $28,3{ }^{\circ} \mathrm{C}$, e picos de temperatura elevada, atingindo $28,5{ }^{\circ} \mathrm{C}$, no bairro Cabreúva - zona residencial com alto adensamento, lotes menores e com baixo índice de vegetação intra-lotes, na região centro-norte da área urbana. 0 relevo na região urbana centro é considerado plano e ondulado somente em áreas de drenagem, e a altitude varia entre 450 e 600 m. A orientação das vertentes nesta região da cidade é voltada para oeste.

Somente após o ponto 32 da coleta que as temperaturas começam a diminuir gradativamente até $\mathrm{o}$ final do trajeto onde atinge $25,1{ }^{\circ} \mathrm{C}$, no prolongamento da Av. Ernesto Geisel denominado Av. Prefeito Heráclito Diniz de Figueiredo, na qual se situa um parque urbano ligado ao Parque Estadual Segredo, grande área de reserva natural.

Nesta parte final do transecto sul-norte Weingartner (2008) cita que existem parques urbanos inseridos no que ele denominou de Setor 4 da área urbana de Campo Grande, a qual possui boa parte das moradias de população de baixa renda de Campo Grande, parques urbanos, muitas das vias não possuem pavimentação, possui áreas vazias, e ainda a deficiência de infraestrutura urbana em geral.

Cabe ainda salientar que no final do trajeto, na porção nordeste da cidade, a orientação das vertentes está orientada a oeste, o que eleva a carga térmica recebida e o relevo é movimentado, ou seja, com ondulações. E a 
altitude é a maior do perímetro urbano, oscilando entre 600 e $750 \mathrm{~m}$, havendo um divisor de águas das bacias Ribeirão das Botas.

Na segunda etapa da pesquisa, nos transectos de inverno, datados de 14 de julho de 2015, foram obtidos dados de temperaturas máximas na Região Urbana Centro e mínimas na zona leste da cidade.

No início do transecto de inverno da Av. Afonso Pena (Figura 4), na porção leste da cidade, as temperaturas aferidas foram mais baixas, em torno de $22{ }^{\circ} \mathrm{C}$, provavelmente devido à proximidade com áreas de vegetação densa como o Parque Estadual do Prosa, Parque dos Poderes e Parque das Nações Indígenas.

A temperatura se eleva gradativamente com a proximidade à área central da cidade, altamente impermeabilizada e altamente adensada, atingindo temperaturas próximas a $26^{\circ} \mathrm{C}$, e ao se afastar da zona de vegetação densa, comprovando que o uso e ocupação do solo modificam a temperatura.

Após passar pela área central, na qual predomina alto adensamento, as temperaturas voltam a decrescer à medida que se aproximam de outra área verde da cidade inserida no entorno do Comando Militar Oeste e proximidades do Aeroporto Internacional de Campo Grande, atingindo $25,5^{\circ} \mathrm{C}$. Até o final do trajeto as temperaturas declinam até chegar nas mínimas aferidas, em locais de vegetação densa e adensamento baixo, com pouco menos de $23^{\circ} \mathrm{C}$.

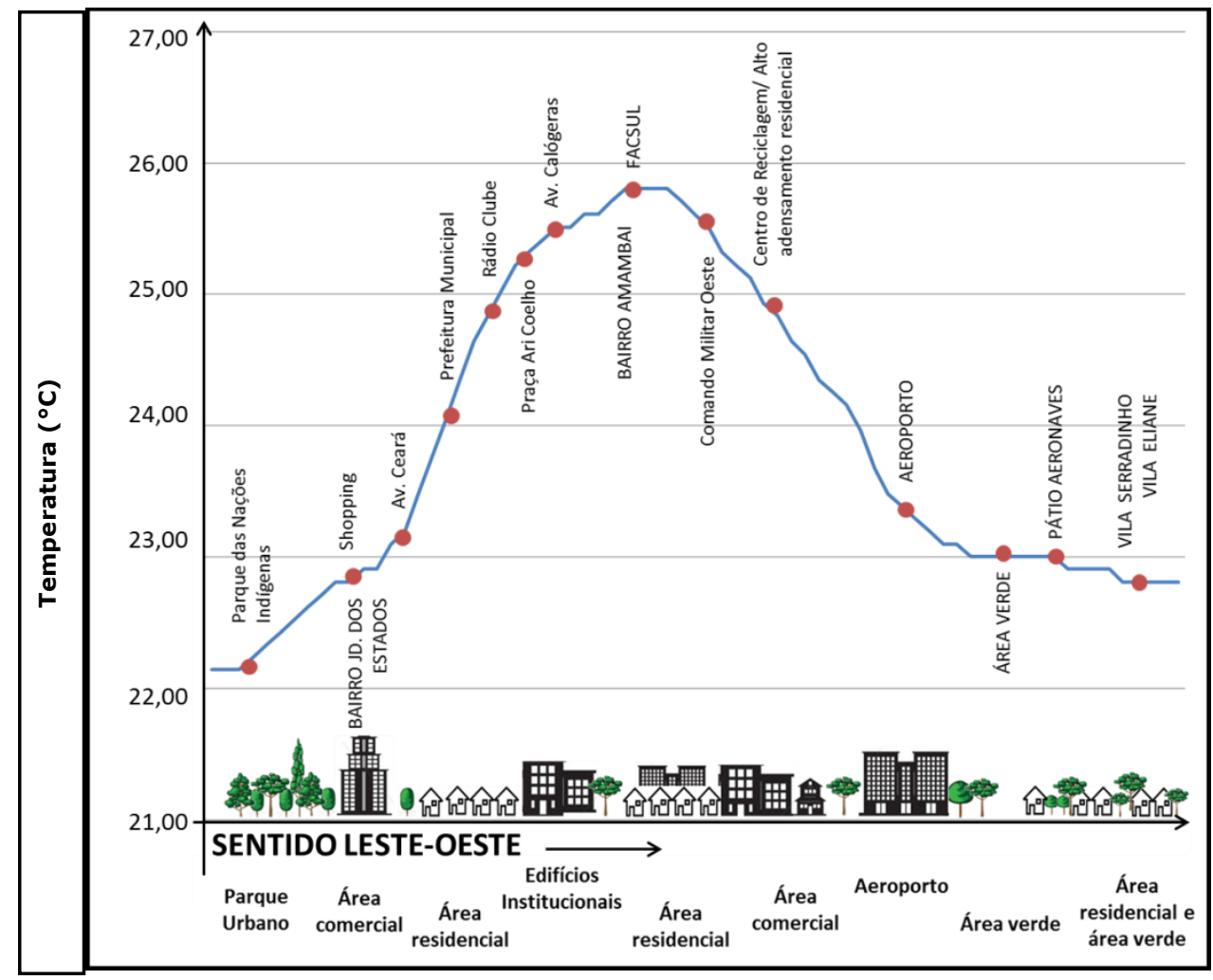

Figura 4 - Distribuição da temperatura ambiente na Av. Afonso Pena e Uso e ocupação do solo através do transecto móvel realizado no inverno, 14 de julho de 2015 , às $20 \mathrm{~h}$. 
A figura 5 mostra o transecto móvel de inverno para a Av. Ernesto Geisel, tendo início na Av. Gunter Hans próximo ao rodoanel, zona industrial da cidade e porção sudoeste da cidade. O alto índice de impermeabilização do solo devido à pavimentação asfáltica, concreto e alvenaria das edificações residenciais e galpões de estrutura metálica evidencia as temperaturas aferidas neste ponto, que foram as maiores do percurso, acima de $25^{\circ} \mathrm{C}$, inclusive nas proximidades do parque urbano de recreação Ayrton Senna.

As temperaturas detectadas na Região Urbana do Centro mativeram-se próximas a $25^{\circ} \mathrm{C}$, ou seja, um pouco menores que as temperaturas aferidas no início do transecto.

Já na última parte do transecto móvel foram detectadas as menores temperaturas, assim como no verão, próximas à Região Urbana Segredo e mais especificamente ao longo do Parque Estadual Segredo e seu entorno.

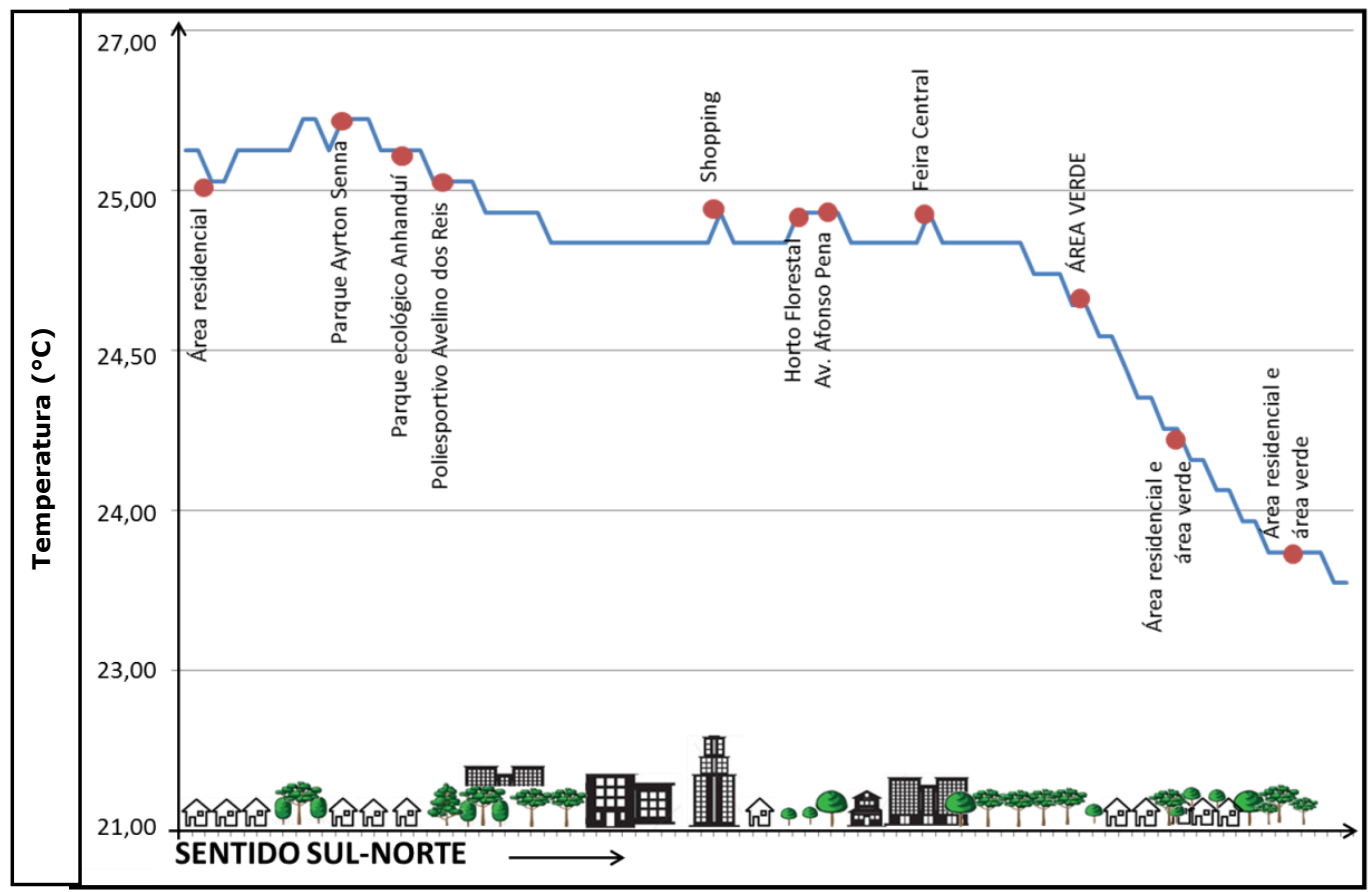

Figura 5 - Distribuição da temperatura ambiente na Av. Ernesto Geisel e Uso e ocupação do solo através do transecto móvel realizado no inverno, 14 de julho de 2015, às $20 \mathrm{~h}$.

Os transectos móveis indicaram que a urbanização e as características do uso do solo são responsáveis pela distribuição da temperatura do ar gerando regiões com temperaturas mais elevadas nos bairros densamente construídos, ou com a concentração de materiais construtivos de grande potencial de emissão de calor ao meio e com alta refletância (valores acima de $28^{\circ} \mathrm{C}$ ).

Este padrão de distribuição, de acordo com Romero (2000) e Amorim (2005), pode se modificar em função da direção do vento e de sua velocidade que pode deslocar essas ilhas de calor para outras áreas da região urbana. 
Durante a noite, a cidade gera ilhas de calor com o aumento da temperatura de bairros menos densamente construídos, em direção aos bairros densamente construídos e em direção ao centro, isso é comprovado pelo fato da convecção funcionar a partir das zonas de alta pressão (zonas mais frias) para as de baixa pressão (zonas mais quentes). Além do fator adensamento, os materiais construtivos também contribuem para a absorção e acúmulo do calor durante o dia e sua liberação durante a noite (Dutra et al., 2003).

Em Campo Grande, o período de seca se estende principalmente durante o inverno, amplificado devido a alterações decorrentes da retirada da vegetação nativa, da impermeabilização do solo e canalização dos córregos e rios presentes no perímetro urbano. Todas estas alterações retiram da superfície os estoques hídricos disponíveis, agravando o período de seca, presente no inverno de Campo Grande, Mato Grosso do Sul.

A temperatura mínima aferida nos transectos de verão foi de $25,03^{\circ} \mathrm{C}$. E a máxima detectada, $28,65{ }^{\circ} \mathrm{C}$ é considerada uma temperatura quente moderado (DUTRA et al., 2003). Sendo assim, as temperaturas noturnas da área urbana, mesmo em áreas mais amenas, provocaram sensação de desconforto térmico no verão de 2015.

Já a temperatura mínima aferida no inverno foi de $22,3^{\circ} \mathrm{C}$, considerada dentro do limite de conforto térmico humano, encontrada apenas em regiões com presença de vegetação densa e preservada em seu entorno. E a máxima detectada, $25,85^{\circ} \mathrm{C}$ é considerada uma temperatura quente moderado (DUTRA et al., 2003). Sendo assim, as temperaturas noturnas tiveram uma oscilação, mostrando a grande relevância da presença de vegetação no ambiente urbano, provocando sensações de conforto a desconforto térmico no inverno de 2015.

Após a etapa de processamento dos dados obtidos pelos transectos móveis, buscou-se também realizar um mapa com as temperaturas do ar com o método de interpolação dos referidos dados coletados.

No mapa de interpolação de dados de verão, primeiramente, foram selecionados todos os pontos dos transectos e o resultado obtido teve correlação estatística baixa, 38\%, mostrando falhas no início do percurso, região Sul da cidade. Posteriormente, foram retirados os quatro primeiros pontos do eixo sulnorte, que estavam causando interferências na interpolação, mas não foi obtido sucesso. O mesmo ocorreu com o mapa de interpolação de dados de inverno. 0 número total de pontos pode ter sido insuficiente para as análises de interpolação de dados.

Com a intenção de estabelecer correlações entre os dados aferidos, optou-se por realizar um mapa de temperatura de superfície da área urbana de Campo Grande, com o uso de imagem Landsat-8, data de passagem 26/04/2015.

As imagens de satélite são favoráveis para estimar a temperatura da superfície, dependendo do tipo de uso e ocupação do solo. Trata-se apenas indiretamente da temperatura do ar ligada às aferidas em abrigos por meio do balanço da energia daquele local. Podendo também auxiliar na compreensão da distribuição das fontes de calor dentro de um perímetro urbano que levam à formação de ilha de calor urbana ou ilha de frescor urbana. 
A distribuição térmica da área urbana interpretada na imagem tratada do Landsat-8 traduz o uso e a ocupação atual das diversas regiões, as densidades de construções e a distribuição e intensidade de arborização em cada região urbana de Campo Grande - MS.

Para validar os dados de temperatura aferidos buscou-se compará-los com a variação de temperatura diária do ar a $150 \mathrm{~cm}$ de altura na estação automática do INMET, para o dia 26/04/2015, que se encontrou a $30,2{ }^{\circ} \mathrm{C}$ às $17 \mathrm{~h}, 29,5^{\circ} \mathrm{C}$ às $19 \mathrm{~h}$, e $28,8^{\circ} \mathrm{C}$ às $20 \mathrm{~h}$, sendo estes os horários próximos aos da captação da imagem termal apresentada nesta pesquisa.

Com esta análise observou-se que a temperatura geral aferida pela estação automática oficial do INMET é semelhante à temperatura de superfície nos locais da área urbana com alto adensamento e baixos índices de vegetação da diferença normalizada (Souza, 2016).

Ressalta-se que o solo no dia 26/04/2015 apresentava-se com baixa umidade devido à escassez de precipitação dos dias anteriores conforme dados CPTEC/INPE INMET, sendo a média total de precipitação, para o mês de abril de 2015, $100 \mathrm{~mm}$ e temperatura média mensal $19^{\circ} \mathrm{C}$.

De acordo com a figura 16 é possível visualizar a distribuição de temperaturas de superfície espacializadas por meio de procedimentos no software IDRISI Selva, a partir das equações citadas no procedimento metodológico de conversão de tons de cinza em radiância.

De acordo com o Plano Diretor de Arborização Urbana, a região urbana Centro e seu entorno são as que possuem prioridade para plantio de árvores por quilômetro $(\mathrm{km})$.

Comparando com o mapa de temperatura de superfície (figura 6), estas áreas se sobrepõem com temperaturas mais altas, classificadas como urbanização densa.

Estes dados elucidam as informações de diversos autores a respeito dos benefícios da distribuição regular de árvores no meio urbano. E sintetizam estudos referentes ao plantio de infraestrutura verde prioritariamente em áreas mais necessitadas Pitton (1997), Stewart (2000), Oke (2003), Ugeda Júnior (2011), Dubreuil et al. (2010), Foissard et al. (2012). 


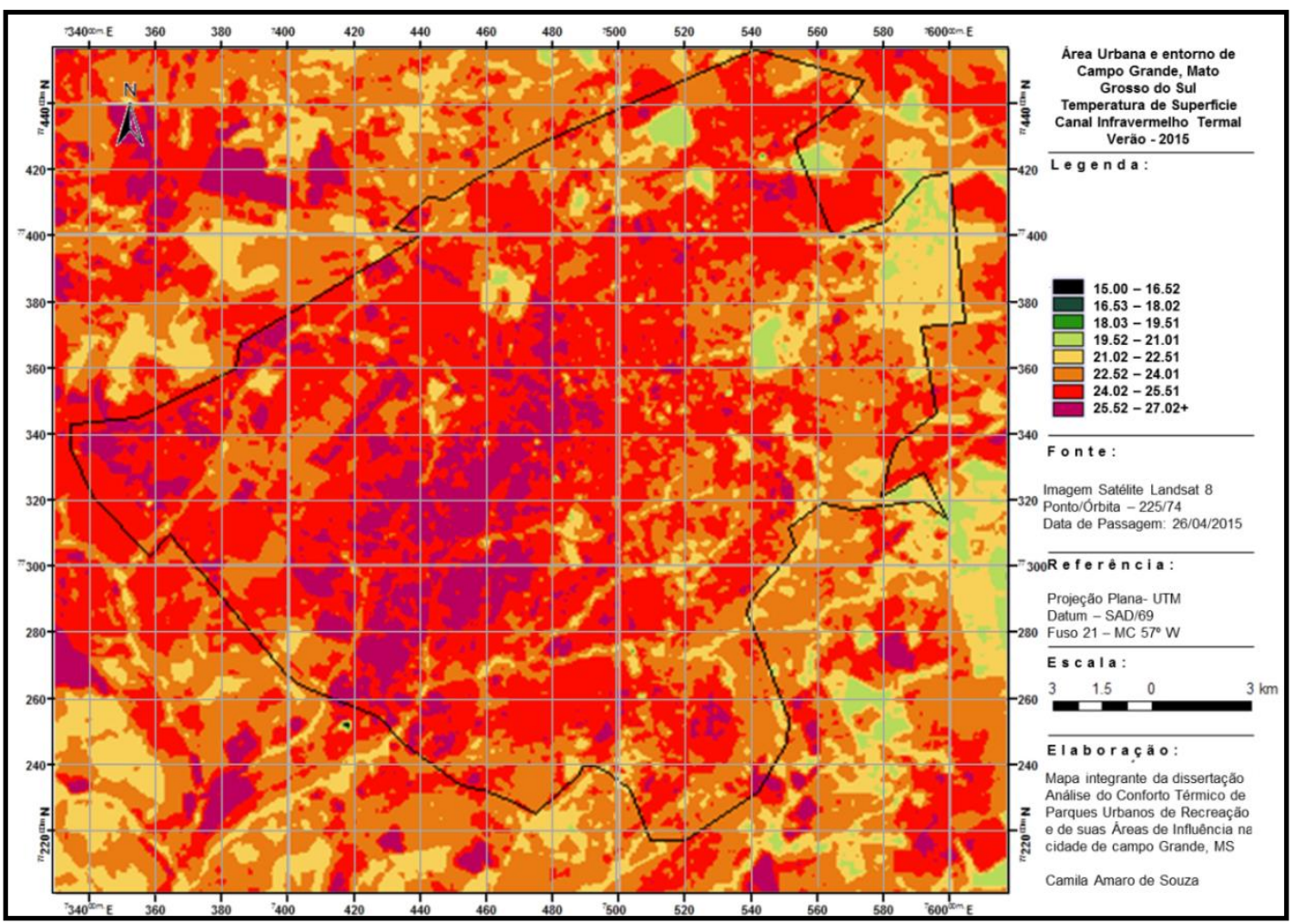

Figura 6 - Mapa de Temperatura de Superfície da Área Urbana de Campo Grande, MS a partir da imagem Landsat-8, data de passagem 26/04/2015.

Nas regiões, ou porções de bairros, densamente construídos, principalmente nos conjuntos habitacionais e em lotes ou glebas com pequena quantidade de vegetação arbórea nas ruas e fundos de quintais, as temperaturas superficiais detectadas foram as mais elevadas, atingindo 27,79 ${ }^{\circ} \mathrm{C}$, sendo os tons de vermelho e magenta no mapa de temperatura de superfície. Na cor magenta do mapa, pode-se detectar temperaturas com cerca de $30^{\circ} \mathrm{C}$ e que podem representar áreas de ilhas de calor urbanas.

Em partes de outras regiões ou bairros com terrenos maiores, em que a área construída não ocupa toda a área do terreno e, com a presença de vegetação arbórea mais disseminada, as temperaturas foram menores (22 a $24,95^{\circ} \mathrm{C}$ ), sendo os tons de laranja e vermelho no mapa.

Nos parques e demais áreas verdes urbanas, as temperaturas variaram entre 15,49 e $19^{\circ} \mathrm{C}$, em função do tipo de vegetação mais rasteira ou arbórea densa, sendo os tons de verde escuro no mapa, constatando o efeito de ilha de frescor.

Parte das Regiões Urbanas à leste, sudeste e extremo norte também registraram temperaturas bastante amenas, entre 15,49 e $21,16{ }^{\circ} \mathrm{C}$, observando os tons de amarelo claro e verde no mapa (Figura 8). As temperaturas mais baixas (entre 15,49 e $19^{\circ} \mathrm{C}$ ) foram observadas nos bairros periféricos pouco construídos, nas cabeceiras de nascentes de córregos, ao longo dos fundos de vale não canalizados e fundamentalmente nos parques 
urbanos de recreação e conservação, onde foram detectados efeito de ilha de frescor.

As zonas de amortecimento de áreas verdes atingiram temperaturas entre 21,16 e $22,11^{\circ} \mathrm{C}$, sendo os tons de verde do mapa.

Em Campo Grande, além do centro da cidade, os bairros mais quentes (acima de $28^{\circ} \mathrm{C}$ ) são os bairros industriais (com prédios com coberturas de fibrocimento) nas saídas sul, sudoeste e noroeste da cidade.

A partir da análise do mapa, a localização das temperaturas mais elevadas, entre 24,95 e $27,79{ }^{\circ} \mathrm{C}$ para tons de vermelho e acima de $28^{\circ} \mathrm{C}$ na cor magenta, do mapa de temperatura de superfície mostrou-se diretamente relacionada à densidade de construções e o excesso noturno de calor, de acordo com Amorim (2005), é atribuído à liberação do calor estocado durante o dia pelas edificações, conforme se observa na imagem tratada do canal termal (banda 10) do Landsat-8 (Figura 8).

Ressalta-se que estes elevados valores de temperatura concentram-se próximos a Região Urbana Centro e dos bairros adjacentes.

Outro fator que potencializa a elevada temperatura nesses ambientes é a ausência quase que total de áreas verdes, constatada com as chaves de interpretação, predominando materiais como concreto, pavimentação asfáltica, proporcionando uma maior emissão de radiação de Ondas Longas (OL) e por sua vez, ocasionando o desconforto térmico.

Sobre esse aspecto Jardim (2010) cita que a presença de áreas verdes nas cidades não se limita ao seu papel de equilibrar o clima urbano, mas também na dosagem de infiltração da água no solo e manutenção do ciclo hidrológico.

Ainda nesse contexto, a diminuição na densidade de construção nas regiões norte, nordeste e sudeste, produz um efeito pronunciado no que se refere à quebra de continuidade da distribuição das temperaturas mais elevadas, bem como a presença de vegetação regularmente distribuída.

Os córregos localizados no ambiente urbano, em sua maioria, foram canalizados ou parcialmente canalizados. No período noturno os pontos com altitudes mais baixas não provocaram a interrupção das altas temperaturas ao longo do trecho sul-norte.

Até mesmo próximo ao Parque Ayrton Senna e Parque Ecológico Anhanduí, onde o Córrego Imbirussu foi amplamente canalizado e a área ao longo dele foi coberta por vegetação rasteira e arbórea, o intenso fluxo de veículos e o uso do solo nas avenidas que margeiam o fundo de vale (comercial e residencial), fizeram com que as temperaturas permanecessem elevadas (27 $\left.{ }^{\circ} \mathrm{C}\right)$.

Assim, pode-se afirmar que, de acordo com Amorim, Sant'Anna e Dubreuil (2009), a presença e boa distribuição da vegetação nas ruas e fundos de quintais tem papel fundamental para amenizar as altas temperaturas durante o dia, no verão. Fato também observado na imagem tratada do Satélite Landsat-8 (Figura 8), mas no período noturno, conforme se verificou nesta pesquisa, a presença da vegetação nas ruas e fundos de quintais não contribuiu 
para amenizar as altas temperaturas em áreas densamente construídas da cidade.

Assim, Campo Grande, cidade de médio a grande porte, com características de clima tropical, produziu um clima urbano que é resultado da interação entre a radiação solar recebida e a refletida basicamente pelos tipos de materiais construtivos de edificações de uso residencial, comercial e institucional que armazenam calor durante o dia e que é liberado nas primeiras horas após o por do sol.

Como as cidades tropicais são naturalmente quentes, essas ilhas de calor são responsáveis pela intensificação do desconforto térmico e, portanto, podem ser consideradas como um indicador de queda da qualidade ambiental urbana.

\section{CONCLUSÕES (CONSIDERAÇÕES FINAIS)}

Em Campo Grande, a partir dos registros de dados dos transectos móveis, verificou-se que no verão e no inverno, sobretudo durante a noite, acentua-se a presença de ilhas de calor urbano no centro da cidade, principalmente devido ao retorno do calor (radiação infravermelha) influenciado pela presença de áreas altamente urbanizadas e falta de vegetação.

As ilhas de calor ocorrem praticamente em todos os setores da classe de cobertura da terra denominada urbanização densa, resultando em temperaturas de superfície com amplitudes elevadas superiores a $12{ }^{\circ} \mathrm{C}$. Apresentando temperaturas superiores a $28{ }^{\circ} \mathrm{C}$ no verão e com cerca de $25{ }^{\circ} \mathrm{C}$ no inverno, sobretudo na porção central e sudoeste da cidade devido à reduzida cobertura vegetal e alta densidade de equipamentos residenciais, somados aos pavimentos, telhados e outras superfícies típicas da paisagem urbana, bem como a distribuição heterogênea dessas respostas.

As imagens termais geradas revelam ainda que os locais mais quentes não são exclusivos da área urbana do município, mas também em parte dos bairros periféricos e área rural, possivelmente ocasionado pelo predomínio de pastagens, além da presença de outros elementos significativos tais como solo exposto e pedreiras desativadas.

Já o efeito ilha de frescor está situado em parte das regiões Leste e Nordeste da cidade, locais onde o Índice de Vegetação da Diferença Normalizada (NDVI) comprovou valores elevados, ou seja, presença de vegetação densa, e reafirmando os valores mais baixos de temperatura do ar aferidos durante os transectos móveis, revelando a influência e a importância da cobertura vegetal na amenização da temperatura, mostrados por Souza (2016).

Nas áreas onde foram observadas temperaturas mais elevadas, sugerese a implantação do novo plano de arborização urbana de Campo Grande, com distribuição regular e espécies adequadas, para minimizar as altas temperaturas no local e também rever as legislações com o intuito de distribuir mais equitativamente a área verde em meio a área construída, pelas diversas regiões urbanas de Campo Grande.

Por fim, as informações de temperatura da superfície, adquiridas a partir dos procedimentos metodológicos de sensoriamento remoto e de imagens gratuitas do satélite Landsat-8, e o estudo do uso e cobertura da terra 
mostraram-se eficientes. Contribuindo na identificação, na espacialização e na compreensão da dinâmica climática operante de microclimas e, com isso, podendo auxiliar na geração de diretrizes de planos setoriais de arborização, planos diretores urbanísticos e no planejamento urbano e ambiental, no sentido de melhorar o conforto térmico nas regiões urbanas.

Além disso, em um contexto de aquecimento global, o estudo do clima urbano levanta a questão de como os impactos do fenômeno global podem afetar uma cidade, em nível local. Portanto, é necessário compreender os princípios bioclimáticos locais, a fim de avaliar os efeitos futuros do aquecimento global na cidade e iniciar processos de adaptação.

Ainda neste sentido, a colaboração entre os gestores e os pesquisadores do clima deve ser estreitada para se obter melhores escolhas de desenvolvimento e ferramentas de implementação de suporte de decisão compartilhada.

\section{REFERÊNCIAS BIBLIOGRÁFICAS}

AMORIM, M. C. C. T.; SANT'ANNA, J. L.; DUBREUIL, V. Estrutura térmica identificada por transectos móveis e canal termal do Landsat-7 em cidade tropical. Revista de Geografía Norte Grande, Santiago, v.12, n.43, p.65-80, 2009.

AMORIM, M. C. C. T. Intensidade e forma da ilha de calor urbana em Presidente Prudente/SP. Geosul, Florianópolis, v.20, n.39, p.65-82, 2005.

COELHO, N. L. A. Distribuição das classes de temperatura de superfície a partir da faixa do infravermelho termal do sensor TM/Landsat-5 no município de Vitória (ES). In: SIMPÓSIO BRASILEIRO DE SENSORIAMENTO REMOTO, 16, 2013, Paraná. Anais... Foz do Iguaçu: INPE, 2013, p.826-833.

COELHO, N. L. A; CORREA, C. S. W. Temperatura de Superfície Celcius do Sensor TIRS/ Landsat - 8. Revista Geográfica Acadêmica, Boa Vista, v. 7, n. 1, p.32-45, 2013.

DUTRA, L.; LAMBERTS, R.; PEREIRA, F. O. R. Eficiência Energética na Arquitetura. 3ed. Rio de Janeiro: Procel/ Eletrobrás, 2003. 366p.

DUBREUIL, V.; QUENOL, H.; FOISSARD, X.; PLANCHON, O. Climatologie urbaine et îlot de chaleur urbain à Rennes. In: CLERGEAU, P. Ville et biodiversité: les enseignements d'une recherché pluridisciplinaire. Rennes: Universidade de Rennes2, 2010. p.105-122.

FOISSARD, X.; CANTAT, O.; DUBREUIL, V.; SAVOURET, E.; QUENO, L. H.; BENSAID, A.; PLANCHON, O. Climat urbain, changement climatique et types de temps dans le Grand Ouest de la France. In: MEROT, P. Le climat change dans I'Ouest, Evaluation, Impacts, Perceptions. Rennes: Universidade de Rennes2, 2012. p.73-92.

GARTLAND, L. Ilhas de calor: como mitigar zonas de calor em áreas urbanas. São Paulo: Oficina de Textos, 2010. 248p.

GEIGER, R. Manual de microclimatologia - o clima da camada de ar junto ao solo. 2ed. Lisboa: Fundação Calouste Gulbenkian, 1990. 639p. 
JARDIM, C. H. Variações da temperatura do ar e o papel das áreas verdes nas pesquisas de climatologia urbana. Revista de Ciências Humanas, Viçosa, v.10, n.1, p.9-25, 2010.

LIMA, R. C. Estudo do campo térmico urbano por meio do sensoriamento remoto: o caso de Campo Grande (MS). 2011. 79f. Dissertação (Mestrado em Geografia) - Universidade Federal de Mato Grosso do Sul, Três Lagoas.

MENDONÇA, F. de A. O clima e o planejamento urbano de cidades de porte médio e pequeno: proposição metodológica para estudo e sua aplicação à cidade de Londina/PR. 1994, 299 f. Tese (Doutorado em Geografia) - Universidade de São Paulo, São Paulo, 1994.

MONTEIRO, M. A. O clima urbano do Porto: contribuição para a definição das estratégias de planejamento e ordenamento do território. São Paulo: Fundação Calouste Gulbenkian, Junta Nacional de Investigação Científica e Tecnológica, 1997. 485p.

OKE, T. R. Thermal remote sensing of urban climates. Remote Sensing of Environment, Nova York, v. 86, n. 3, p. 371-384, 2003.

PIRAJÁ, R. V. Análise geoambiental da região do Imbirussu, Campo Grande, Mato Grosso do Sul. 2013. 85f. Dissertação (Mestrado em Desenvolvimento Regional e Meio Ambiente) - Universidade Anhanguera-Uniderp, Campo Grande.

PITTON, S. E. C. As cidades como indicadores de alterações térmicas. 1997. 272f. Tese (Doutorado em Geografia Física) - Faculdade de Filosofia, Letras e Ciências Humanas, Universidade de São Paulo, São Paulo.

PLANURB. Relatório de Avaliação Ambiental (RAA). Programa de Desenvolvimento Integrado e Qualificação Urbana de Campo Grande/MS - Viva Campo Grande. 2007. Disponível em: <http://www.pmcg.ms.gov.br/planurb/downloads?categoria=36> Acesso em: 28 jun. 2015.

PLANURB. Instituto Municipal de Planejamento Urbano. Perfil Socioeconômico de Campo Grande. $17^{\circ}$ ed. revista. Campo Grande, 2010.

ROMERO, M. A. B. Princípios bioclimáticos para o desenho urbano. São Paulo: ProEditores, 2000. 128p.

SOUZA, C. A. Análise do conforto térmico de parques urbanos de recreação e de suas áreas de influência, na cidade de Campo Grande, Mato Grosso do Sul. 2016. 139f. Dissertação (Mestrado em Desenvolvimento Regional e Meio Ambiente) - Universidade Anhanguera-Uniderp, Campo Grande.

STEWART, I. D. Influence of meteorological conditions on the intensity and form of the urban heat island in Regina. The Canadian Geographer, Toronto, v. 44, n. 3, p. 271-285, 2000.

UGEDA JÚNIOR, J. C. Clima urbano e planejamento na cidade de Jales-SP. 2011. 383f. Tese (Doutorado em Geografia). Universidade Estadual Paulista, Presidente Prudente.

USGS. Geological Survey / Serviço de Levantamento Geológico Americano. Imagens orbitais digitais gratuitas do satélite Landsat-8: data de passagem 26/04/2015 EUA. Acesso em 29 de jun. 2015. Disponível em $<$ http://landsat.usgs.gov>. 
WEINGARTNER, G. A Construção de um Sistema. Os espaços livres públicos de recreação e de conservação em Campo Grande - MS. 2008. 192f. Tese (Doutorado em Arquitetura e Urbanismo) - Faculdade de Arquitetura e Urbanismo, Universidade Estadual de São Paulo, São Paulo. 